\title{
LASER ULTRASONIC MEASUREMENT OF MECHANICAL DECAY IN LIMESTONE CAUSED BY FREEZE-THAW CYCLES
}

\author{
Alexander Kravcov $^{a, *}$, Ondřej FraneK ${ }^{a}$, Nikolaj Morozov ${ }^{a}$, \\ Michą Kucewicz ${ }^{b}$, Michae Tomaszewski ${ }^{b}$, Pavel Svoboda ${ }^{a}$, \\ PAWEE BARANOWSKI ${ }^{b}$
}
${ }^{a}$ Czech Technical University in Prague, Faculty of Civil Engineering, Department of Construction Technology, Thákurova 7, 16000 Prague, Czech Republic
${ }^{b}$ Military University of Technology, Faculty of Mechatronics and Aviation, Institute of Armament Technology, gen. W. Urbanowicza, 00-908 Warsaw, Poland
* corresponding author: kravtale@fsv.cvut.cz

\begin{abstract}
In this article, an innovative new method of non-destructive testing for estimating the sensitivity of limestone is presented. An advantage of the laser ultrasonic structuroscopy method is the time and the quality, due to which less tests are necessary for an analysis of rock properties. Limestone is measured with an innovative structural control method, which shows a good qualitative and quantitative agreement with the basic structural analysis.
\end{abstract}

KEYWORDS: Exterior cladding material, civil construction, laser ultrasonic structuroscopy.

\section{INTRODUCTION}

Limestone is one of the most widely used construction materials in Central Europe. It has a fairly high pore value and is flexible for work. Highly porous limestone is especially susceptible to weathering.

The study of porous limestone samples was aimed at studying the effect of an enclosed water on the mechanical properties after an exposure to freezing [1]. It is reliably known that the influence of a closed water content on the mechanical properties of porous limestone is quite similar as other lithologies [2].

There are a large number of published articles with accurate studies of mechanical parameters, such as bulk density, effective porosity, ultrasonic pulse velocity and compressive strength [3]. It should be noted that after a stable period when isolated microcracks appear, the destruction of the rock occurs in a small number of cycles. The rapid growth of microcracks is caused by the thermal expansion of pore water.

It was found that the physico-mechanical properties of the stone can be reduced over a wide range towards the initial values after freezing and thawing cycles. Nowadays, a study of the influence of temperature differences, with the aim to predict physical and mechanical properties, is the topic of focus.

Traditional mechanical tests are the most commonly used, but they require a large volume of test samples, which, in turn, increases the costs. One way to reduce this item of expenditure may be to partially replace traditional destructive tests with non-destructive methods of time-to-failure data. Ultrasonic structuroscopy allows to obtain the relevant values of the elastic modules and their distribution in the array of samples. Taking into account the fact that the requirements for the geometry of the test samples are lower, the use of ultrasonic methods to determine elastic moduli leads to a reduction in the required volume of samples.

Ultrasonic methods are used for the detection of surface and internal defects, measurement of the thickness of layers in multilayer materials, and an evaluation of volumetric mechanical properties based on longitudinal and shear wave velocities. These applications usually use the frequency range from 50 to $500 \mathrm{kHz}$, which makes it possible to examine samples tens of centimetres thick with a spatial resolution of up to $1 \mathrm{~cm}$. The use of frequencies above $1 \mathrm{MHz}$ is limited because of their strong attenuation in limestone [4 6].

Spatial resolution can be higher, provided that the amplitude of the ultrasonic probe pulse is several orders of magnitude greater and the frequency is a few tens of MHz. This can be attained [7, 8] by means of laser-based excitation of acoustic pulses and reception of ultrasonic energy by a broadband piezoelectric transducer [9]. The use of a Q-switched laser generating pulses with a duration of around $10 \mathrm{~ns}$ and energy of several mJ, which in turn generates ultrasonic pulses with less than 70 ns duration and a pressure amplitude of up to $1 \mathrm{MPa}$, allows achieving an excellent spatial resolution of about $50 \mu \mathrm{m}$ [10]. Therefore, it is possible to detect a variety of microstructures and heterogeneities and assess their dimensions (size of crystals, porosity, and degree of weathering) in pulse-echo mode.

This paper describes a study of local physical and mechanical characteristics after freeze-thaw cycles of limestone samples by laser ultrasonic spectroscopy, which is able to define local elastic modules of materials. 


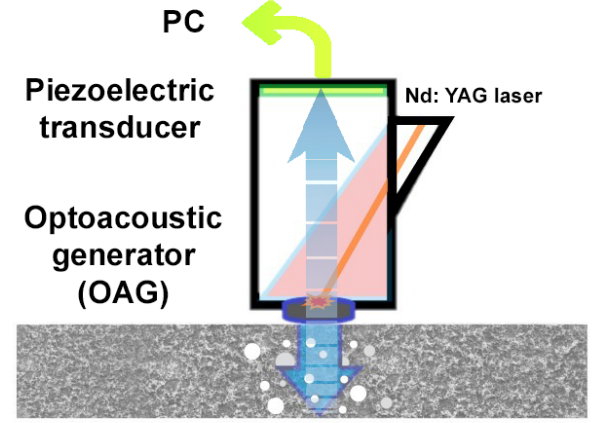

Figure 1. Schematic diagram of optoacoustic generator.

\section{MATERIALS AND METHODS}

\subsection{Optoacoustic EQUipment AND MEASURING TECHNIQUE}

Laser ultrasonic structuroscopy is similar to traditional ultrasonic systems operating in echo-pulse mode. The generation of ultrashort high-power ultrasonic pulses with a strictly controlled form occurs in an optoacoustic cell based on the generation of ultrasonic pulses by thermal expansion. A pulse generated by a laser is transmitted to the front side of a special optoacoustic generator (OAG). Figure1 1 shows a schematic diagram of this cell for the diagnostics of materials at one-side access.

The pulse energy enters the sample and is scattered by its heterogeneities and reflected from the back side of the sample. In the case of sufficiently strong scattering (which is indicative of a high degree of heterogeneity), the reflection from the back side may not be observed [11, 12]. All scattered and reflected signals are recorded by the piezoelectric transducer and processed by a processing system. The surface of the sample is scanned with a $1 \mathrm{~mm}$ step. Provided that the reflection from the back side of the sample is distinctly recorded (no defects and low porosity), the phase velocity of the longitudinal ultrasonic waves can be evaluated by the difference between the arrival times of the minimum of the reflection from the back side and the maximum of the reflection from the OAGsample interface [13].

Note that an S-wave pulse is recorded in the interval between the first and second reflections of $\mathrm{P}$-waves from the back side; the time delay of the S-wave's arrival can be used to calculate its velocity. In the course of scanning, local velocities are determined. The velocities dependent on density are related to local modules of elasticity; they can be calculated as follows:

$$
\begin{gathered}
E=\rho C_{t}^{2}\left[3-\frac{1}{x^{2}-1}\right] \\
\nu=\frac{x^{2}-2}{2\left(x^{2}-1\right)}
\end{gathered}
$$

$$
G=\rho C_{t}^{2}
$$

where: $E$ is Young's modulus, $G$ is shear modulus, $\nu$ is Poisson's ratio, $\rho$ is the calculated density of the sample, $C_{t}$ is the measured value of shear acoustic wave velocity in the sample, $\mathrm{m} / \mathrm{s} ; C_{l}$ is the measured value of longitudinal acoustic wave velocity in the sample, $\mathrm{m} / \mathrm{s} ; x=C_{l} / C_{t}$ is the ratio of the longitudinal and shear wave velocities.

Based on the above-described, it is possible to map ultrasonic wave velocities, elastic moduli, and porosity $\mathrm{P}$ using the expression.

\subsection{SAMPLES}

According to mineralogical features, the tested rock samples are medium-grained porous limestone; in most cases, they contain interlayers of marl.

Using electron microscopy, the pore sizes, their location in space, and the bulk porosity of the samples were studied. Figures $2 \mathrm{a}$ and $2 \mathrm{~b}$ present electronic images of samples with pores and structural inhomogeneities characteristic for these samples. The size of grain ranges from $50 \mu \mathrm{m}$ to $400 \mu \mathrm{m}$; most grains usually have a size of $200 \mu \mathrm{m}$, porosity varies from 2 to $7 \%$.

The physical and mechanical properties of the samples are as follows: the average density is $2827 \mathrm{~kg} / \mathrm{m}^{3}$, the ultimate compression strength varies from 85 to $140 \mathrm{MPa}$, average water absorption is $2.76 \%$. The samples studied are rectangular parallelepipeds with the characteristic dimensions $65 \mathrm{~mm}, 65 \mathrm{~mm}$, and $5 \mathrm{~mm}$.

\section{Results}

The study of samples took place in 2 stages. In the first stage, the elastic moduli and porosity of the samples were determined. Then, the samples were exposed to 20 cycles of freezing based on EN 12371 recommendations for Natural Stone tests methods: determination of frost resistance, and thawing in temperatures ranging from $300 \mathrm{~K}$ to $253 \mathrm{~K}$. After the freeze-thaw cycles, the samples display clear fractures as the main weathering pattern. After the freezing and thawing cycles, the samples were re-scanned by the laser-ultrasound device. The samples were scanned with a step of $300 \mu \mathrm{m}$ to $1 \mathrm{~mm}$.

Defect-free limestone samples were selected to be further examined. Figures 3 , $4 a$ and $4 b$ show maps of elastic wave velocities, elastic modules and porosity for one of the samples. Clearly, this limestone sample is quite homogeneous, longitudinal and shear wave velocities vary from 4710 to $4830 \mathrm{~m} / \mathrm{s}$ and from 1640 to $1675 \mathrm{~m} / \mathrm{s}$, respectively; Young's modulus and Poisson's ratio vary from 38.0 to 40.5 and from 0.403 to $0.408 \mathrm{GPa}$, respectively. Porosity has a medium value, about $2.7 \%$.

After 20 freezing and thawing cycles, samples display clear fractures and the porosity of the samples increased significantly, which led to a decrease in Young's modulus by an average of $20 \%$ (Figure $5 \mathrm{a}$ and $5 \mathrm{~b})$. 


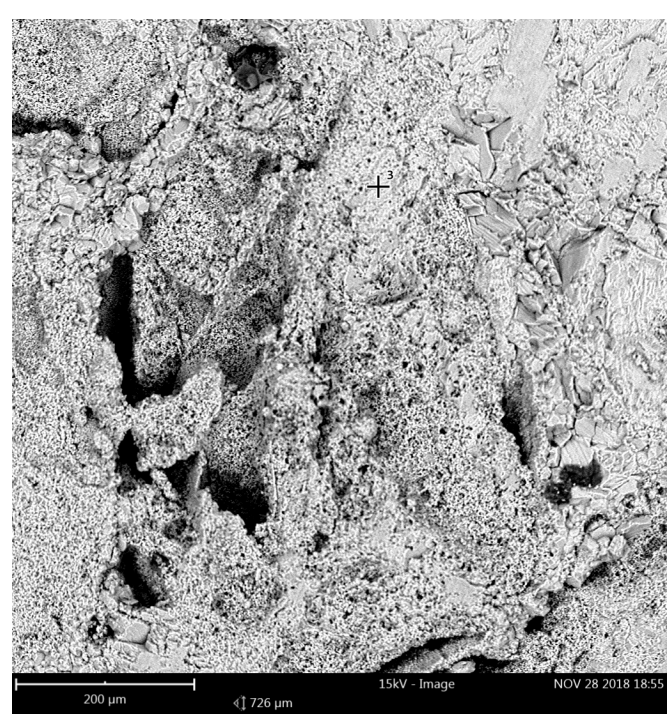

(A).

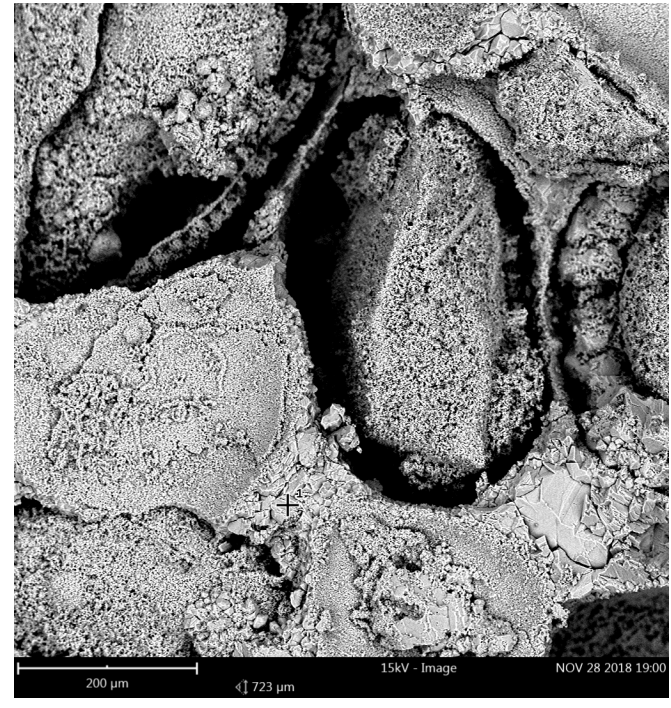

(B).

Figure 2. Phenom ProX3 SEM images of polished sections.

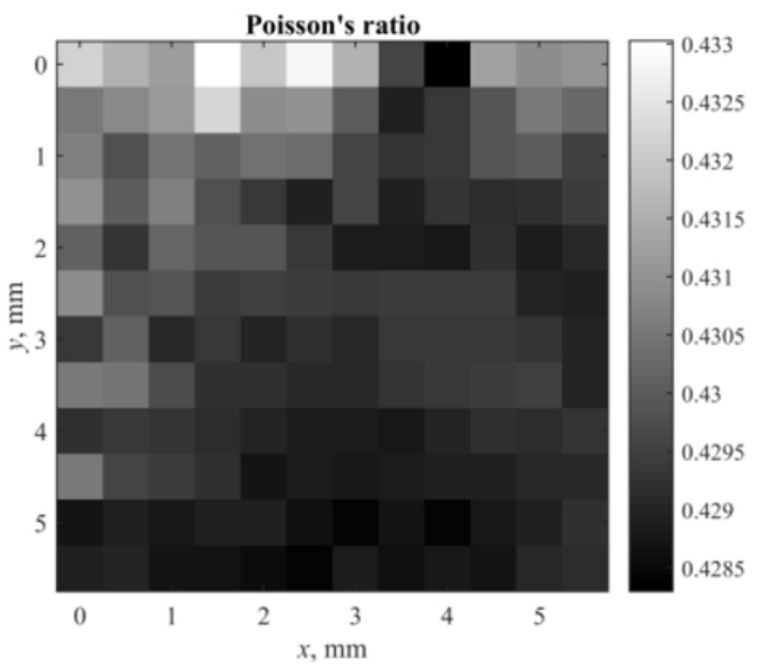

Figure 3. Poisson's ratio map of limestone sample.

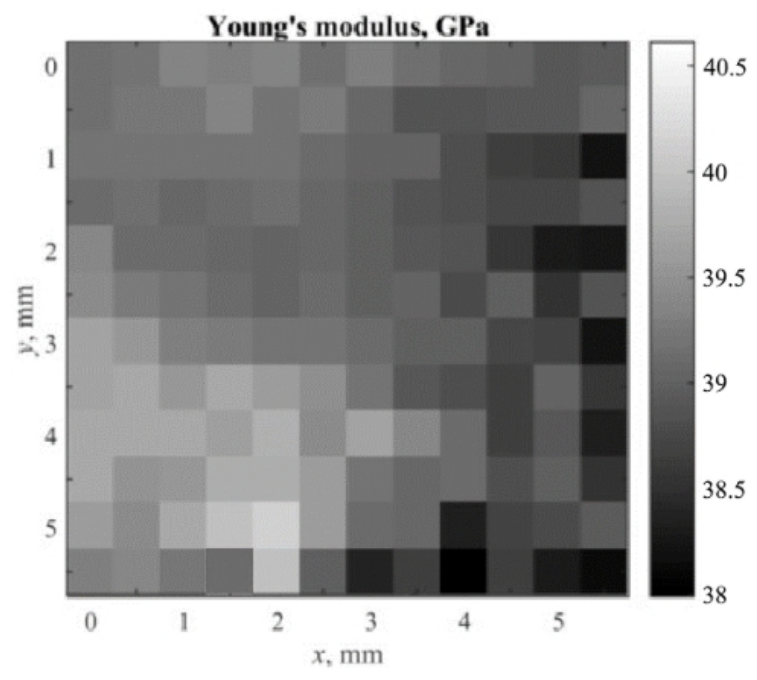

(A).

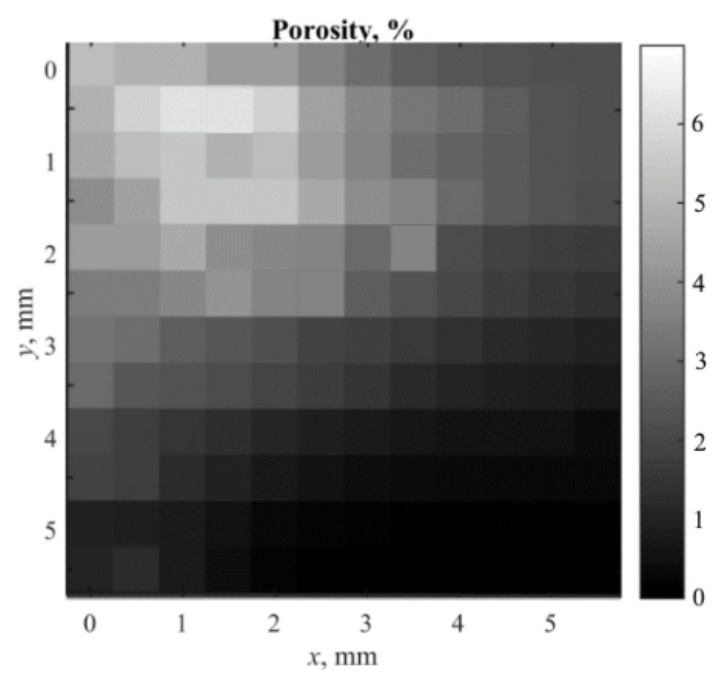

(B).

Figure 4. Poisson's ratio map of limestone sample. 


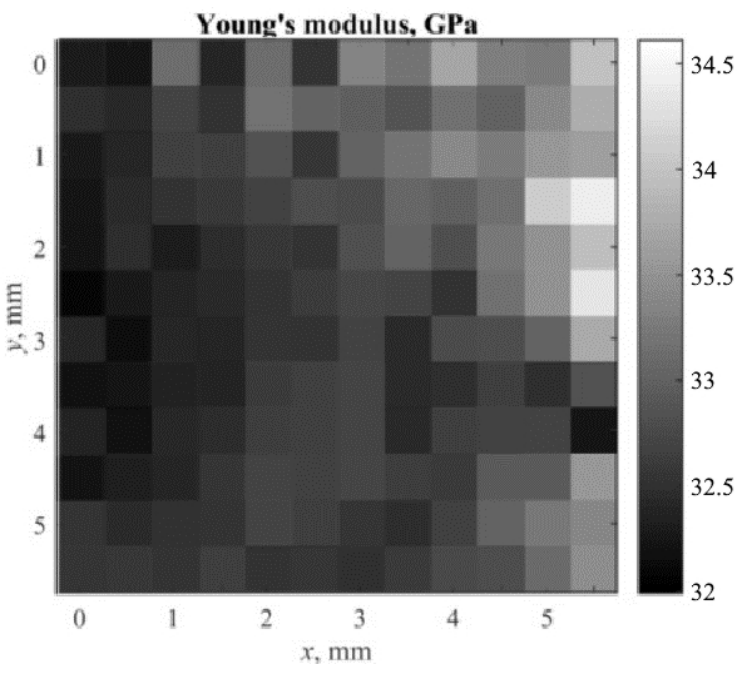

(A).

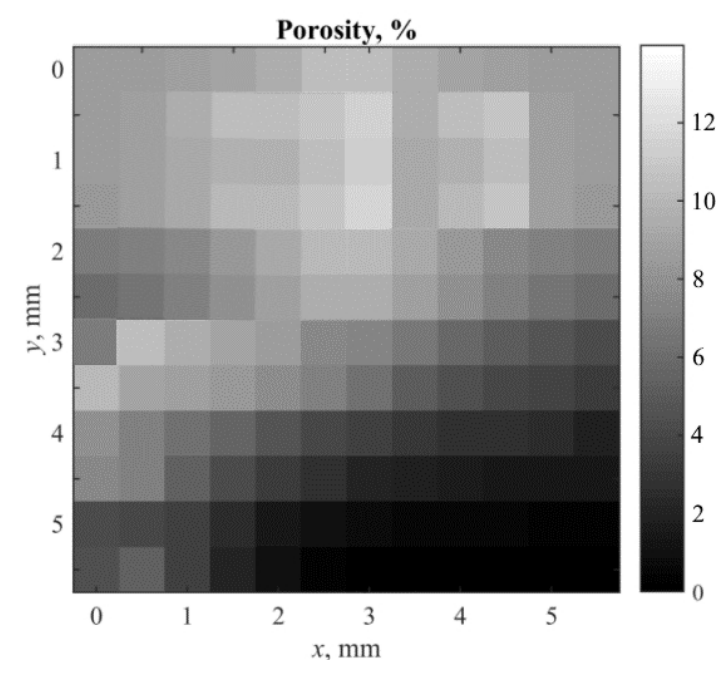

(в).

Figure 5. Young's modulus and Porosity maps of limestone sample after of freezing and thawing.

\section{Conclusion}

The loss of durability of medium-grained porous limestone is related to the creation of new void volume due to an expansion of water closed in pores during freezethaw cycles. Ice crystals crack the internal structure, forming an additional water filling systems. Affected samples absorb more water due to the newly created pore volume. As expected, the diminution of adhesion of grain bonders and the increase of pore capacity vastly reduce the obtained load resistance after 20 freeze-thaw cycles.

The degree of strength reduction depends on the porosity and the natural fissuring of the rocks. In the experiments, it was observed that with increasing porosity, the compressive strength of rocks decreases. The compressive strength of the samples fell by $30 \%$ after the exposure to 20 freeze-thaw cycles.

\section{ACKNOWLEDGEMENTS}

This study was financially supported by the National Ministry of Education of Czech Republic (No. 027/0008465) and Warszawa War Studies Academy endowment. The authors are grateful to the Czech Technical University in Prague, they would also want to thank Prof. Jerzy Malachowski from the Military University of Technology and Lt.Col. Paweł Maciejewski from War Studies Academy, both in Warszawa, for their advices.

\section{REFERENCES}

[1] B. Vásárhelyi. Statistical analysis of the influence of water content on the strength of the miocene limestone. Rock Mechanics and Rock Engineering 38:69 - 76, 2005. DOI:10.1007/s00603-004-0034-3.

[2] B. Vásárhelyi, P. Ván. Influence of water content on the strength of rock. Engineering Geology 84(1):70 - 74, 2006. DOI:10.1016/j.enggeo.2005.11.011.

[3] J. Martínez-Martínez, D. Benavente, M. Gomez-Heras, et al. Non-linear decay of building stones during freeze-thaw weathering processes. Construction and
Building Materials 38:443 - 454, 2013. DOI:10.1016/j.conbuildmat.2012.07.059

[4] J. Štoller, E. Zezulová. Use of ultrasound - The ultrasonic pulse velocity method for the diagnosis of protective structures after the load of TNT explosion. In ICMT 2017 - 6th International Conference on Military Technologies, pp. 230 - 235. 2017. DOI:10.1109/MILTECHS.2017.7988761.

[5] J. Štoller, P. Dvořák. Ultrasound diagnosis of protective structures after contact explosion. In Transport Means 2014, pp. 264 - 267. Kaunas University of Technology, Lithuania, 2014.

[6] S. N. Iliopoulos, L. De Smet, D. G. Aggelis. Investigating ultrasonic wave dispersion and attenuation in fresh cementitious materials: A combined numerical, analytical, and experimental approach. NDT / $\mathscr{E} E$

International 100:115 - 123, 2018. DOI:10.1016/j.ndteint.2018.09.005.

[7] D. Ciofini, A. A. Mencaglia, S. Siano. A photoacoustic pulse-echo probe for monitoring surface stone mechanical properties: Validation tests in consolidation of Carrara marble. Construction and Building Materials 187:610 619, 2018. DOI:10.1016/j.conbuildmat.2018.07.225

[8] A. Kravcov, O. L. Dudchenko, P. Svoboda, P. Ivanov. Broadband ultrasonic pulse-echo method for estimation of local density of tungsten samples. Journal of Physics: Conference Series 1047:1 - 5, 2018. DOI:10.1088/1742-6596/1172/1/012064

[9] A. Kravcov, I. Shibaev. Measurement of local mechanical characteristics of marble by broadband ultrasonic structuroscopy. International Journal of Civil Engineering and Technology 10:35 - 42, 2019.

[10] A. N. Kravcov, P. Svoboda, A. Konvalinka, et al. Laser-ultrasonic testing of the structure and properties of concrete and carbon fiber-reinforced plastics. In Special Concrete and Composites 2016, vol. 722 of Key Engineering Materials, pp. 267 - 272. 2017. DOI:10.4028/www.scientific.net/KEM.722.267 
[11] P. Svoboda, V. Pospíchal, A. Kravcov, et al. Quality assessment of bored pile foundations by a set of nondestructive testing methods. In ICMT 2019 International Conference on Military Technologies. 2019.

[12] A. Kravcov, I. Shibaev. Examination of structural members of aerial vehicles by laser ultrasonic structuroscopy. International Journal of Civil Engineering and Technology 9(11):2258 - 2265, 2018.
[13] A. Kravcov, P. Platek, W. Koperski, V. Pospíchal. Internal structure research of 3D printed cellular structures by laser-ultrasonic structuroscopy. In 2019 International Conference on Military Technologies (ICMT), pp. 1-7. 2019. DOI:10.1109/MILTECHS.2019.8870047. 